\title{
Laws that are Made to be Broken
}

\author{
James Edwards ${ }^{1}$
}

Published online: 5 October 2017

(C) The Author(s) 2017. This article is an open access publication

\begin{abstract}
Criminal laws are created to achieve various ends. These include (1) reducing the incidence of wrongdoing, and (2) holding wrongdoers responsible for their wrongs. Some criminal laws are created to further the first of these ends by means of compliance. The second end is to be furthered only if, regrettably, some fail to comply. These criminal laws are made to be followed. Other criminal laws are not created with compliance in mind. Conviction, in these cases, is no regrettable fallback. It is the primary means by which the law is to contribute to ends (1) and (2). Laws of this second kind are made to be broken. My concern in this paper is with the creation of such laws. Section 1 sharpens the contrast drawn above, and considers some arguments for enacting laws that are made to be broken. The following sections develop an argument against. Section 2 introduces what I call the identification principle. It argues that the principle is an implication of the ideal of the rule of law, and that it binds state officials who make, apply and enforce criminal laws. Section 3 argues that when laws are made to be broken, the identification principle is violated. Section 4 concludes.
\end{abstract}

Keywords Criminalization · Rule of law · Transparency $\cdot$ Protection

I am grateful to audiences at Bocconi University and Universidad Carlos III de Madrid. Thanks to Ricardo Cueva, who was my commentator in Madrid, and to Annalise Acorn, Andrea Dolcetti, Damiano Canale, Hasan Dindjer, Timothy Endicott, Fabrizio Esposito, John Gardner, Ambrose Lee, and Giovanni Tuzet for discussion.

James Edwards

james.edwards@law.ox.ac.uk

1 Worcester College, University of Oxford, Oxford OX1 2HB, UK 
Many worry, nowadays, that we live in a world with too much law. This worry is expressed with particular force in the literature on criminal law. A crisis of overcriminalization, it is there claimed, afflicts the legal systems in which we live. ${ }^{1}$ Obviously enough, these claims presuppose some standards that determine how much criminal law there ought to be. The task of identifying these standards is a formidable one. In this paper, I attempt to make a modest contribution to that task. I argue that the criminal law should not contain laws that are made to be broken. Section 1 explains what these laws are and why they might be (and are) created. Section 2 discusses what I call the 'identification principle.' It argues that the principle is an implication of the ideal of the rule of law, and that it binds state officials who make, apply, and enforce criminal laws. Section 3 argues that, when laws are made to be broken, the identification principle is violated. Section 4 concludes by considering the implications of the argument for the criminal law's pursuit of justice.

\section{Two Types of Law}

Scholarship on criminalization revolves around the following master question: what, if anything, is it morally permissible to make a crime? If we hope to answer, we should start with some distinctions. One is between reasons and permissibility. We have reason to do something if one or more considerations count in its favour. We are permitted to do something if the reasons to do it are undefeated by any that countervail. We often have reason to do what we are not permitted to do. That it will quench my thirst is a reason for me to drink your orange juice. But, if you have not consented to my doing so, it is impermissible for me to take a drink. To make progress with the question of permissible criminalization, we must say something about both the reasons that count in its favour, and those that count against. We cannot hope to know whether, and when, the latter reasons defeat the former without knowing what the former are. And we cannot hope to know whether, and when, the former survive defeat until we have identified the latter.

A second distinction is between normative and motivating reasons. The previous paragraph was concerned with normative reasons. A consideration may count in favour of ping-it may be a normative reason to $\varphi$ - even if no-one ever $\varphi s$ (even in part) because it so counts. And people may $\varphi$ (partly) because they take some consideration to count in favour of ping, even if it does not so count, or even counts in the other direction. The considerations people take to count in favour of their actions are their motivating reasons. Though motivating reasons should always be normative reasons, ${ }^{2}$ normative reasons should not always be motivating. Those that should not are excluded in Joseph Raz's sense. $^{3}$ The fact that I will enjoy a morning in bed is a normative reason to stay there. But that reason is excluded by my promise to meet you in town for breakfast. It is not a reason for which I should act, at least this morning. It should not figure among my motivating reasons.

Exclusion is one way in which normative reasons can be defeated. I already claimed that a theory of permissible criminalization is a theory that tells us when the normative reasons to criminalize are undefeated by those that countervail. Such a theory must thus say something about motivating reasons too. It must tell us when normative reasons that favour criminalization should not be motivating reasons for law-makers. Consider an example: if

\footnotetext{
1 The most sustained analysis of the crisis is Douglas Husak's: see D Husak, Overcriminalization (Oxford: Oxford University Press, 2008).

${ }^{2}$ For discussion, see J Gardner, Offences and Defences (Oxford: Oxford University Press, 2007), p. 100ff.

3 J Raz, Practical Reason and Norms (2nd edn, Oxford: Oxford University Press, 1999), p. $35 \mathrm{ff}$.
} 
criminalizing ping is likely to result in more people being prosecuted and punished, this may result in the creation of employment opportunities for those who are badly off (in the police force, the prosecution service, the courts, the prison service, the parole board, etc.). One might plausibly claim that this is a normative reason to criminalize ping. But one might also plausibly claim that law-makers should not criminalize for this reason. In the absence of further normative reasons in favour, it would then be impermissible to criminalize $\varphi$ ing.

A third distinction is between ends and means. Both are considerations that figure among our motivating reasons: nothing counts as one of our ends, or as our means to an end, unless we act because doing so will bring that thing about. This is how both ends and means are distinguished from side-effects. But ends are those things we seek to bring about for their own sake; means are the things we seek to bring about because bringing them about is a way of achieving (or making it more likely that we will achieve) our ends.

We saw above that part of a theory of permissible criminalization would distinguish between those normative reasons for which law-makers may and may not act when they criminalize. We can now add that this part of our theory would also distinguish ends from means. It would identify those things that law-makers may seek to bring about for their own sake when criminalizing. Call these things 'criminalization's ends.' And it would identify those things which law-makers may seek to bring about when criminalizing, as a way of achieving criminalization's ends. Call these things 'criminalization's means.'

Most discussions of reasons to criminalize are plausibly thought of as discussions of criminalization's ends. Joel Feinberg writes that his work is addressed to members of an 'ideal legislature in a democratic country. ${ }^{4}$ So one may plausibly read him as offering a list of normative reasons that are unexcluded when democratic legislators cast their votes for criminal laws. Consider the following entries:

(A) It is always a good reason in support of penal legislation that it would probably be effective in preventing (eliminating, reducing) harm to persons other than the actor (the one prohibited from acting) and there is probably no other means that is equally effective at no greater cost to other values. ${ }^{5}$

(B) It is always a good reason in support of a proposed criminal prohibition that it is probably necessary to prevent serious offense to persons other than the actor and would probably be an effective means to that end if enacted. ${ }^{6}$

(C) It is always a good reason in support of a proposed prohibition that it is probably necessary to prevent harm (physical, psychological, or economic) to the actor himself. $^{7}$

Each of (A)-(C) purports to identify an end of criminalization-something law-makers may seek to bring about for its own sake when they criminalize. ${ }^{8}$ Each end is also preventive: what there is unexcluded reason to bring about, on these views, is a state of

\footnotetext{
${ }^{4}$ Feinberg, Harm to Others (Oxford: Oxford University Press, 1984), p. 4.

5 Ibid., p. 26.

6 Ibid.

7 Ibid., pp. 26-27.

${ }^{8}$ Feinberg endorses (A) and (B) while rejecting (C).
} 
affairs in which there is less harmful wrongdoing, or less wrongdoing that is seriously offensive. ${ }^{9}$ On other views, the ends of criminalization are more numerous. Consider (D) and (E):

(D) It is always a good reason in support of criminalization that it will probably result in wrongdoers offering answers they owe.

(E) It is always a good reason in support of criminalization that it will probably result in just punishment of wrongdoers.

The ends identified by (D) and (E) are responsive: what there is unexcluded reason to bring about, on these views, is a particular response to wrongdoing - the offering of answers by wrongdoers who owe them; the punishments justice demands for wrongdoing.

Preventive and responsive ends are not mutually exclusive. The primary ends of criminalization may be preventive, where primary ends are those we would ideally achieve when all else is equal. But criminalization may also have secondary ends that are responsive, where secondary ends are those we aim to achieve if the ideal is not realized. Exactly which mix of preventive and responsive ends is the right one is a topic for another day. Here, I will simply assume that some such mix is defensible. ${ }^{10}$ My focus will instead be on criminalization's means. It will be, to repeat, on those things that law-makers may seek to bring about when criminalizing, because this is a way of achieving criminalization's ends.

To see what I have in mind, consider two possibilities. First, one might seek to achieve criminalization's ends by means of compliance. We comply with the criminal law when we refrain from criminal conduct, at least partly for the reason that it is a crime. Law-makers who seek to achieve their ends in this way create laws that are made to be followed (LMFs). If their ends are those mentioned in (A)-(C), these law-makers seek to reduce the incidence of harmful or seriously offensive wrongdoing primarily by means of compliance with the laws they create. It does not follow, of course, that those who create LMFs intend for nothing to be done if those laws are broken. They may also intend for offenders to be convicted and punished, both because this furthers responsive ends like those mentioned in (E) and because it furthers preventive ends like those mentioned in (A)-(C). It is important to see, however, that for those who create LMFs this is decidedly non-ideal. Just as responding to wrongdoing is, I suggested above, best seen as a secondary end of criminalization, so conviction and punishment is, for those who create LMFs, a secondary means of achieving preventive ends. It is a way of furthering those ends to which we must regrettably resort when the ideal of compliance has not been realized.

One possibility, then, is that law-makers seek to achieve criminalization's ends primarily by means of compliance. A second possibility is that they seek to achieve those ends primarily by means of conviction. Take a law-maker who assumes that whatever is criminalized, wrongdoers will continue to exist, and who criminalizes primarily because this will result in more wrongdoers being convicted. To seek to achieve one's ends in this way is to create laws that are made to be broken (LMBs). Ex hypothesi, such laws cannot contribute to criminalization's ends, in the way their makers would ideally have them

\footnotetext{
9 I here adopt Feinberg's own understanding of (A)-(C), as principles concerned with the prevention of harmful and offensive wrongdoing, rather than with harm and offence simpliciter. I leave open whether Feinberg's is the best way to understand these principles.

${ }^{10}$ Michael Moore appears to deny this. For replies to his and other objections to the pursuit of preventive ends in criminal law, see J Edwards and A Simester, 'Prevention with a Moral Voice' in Simester, du BoisPedain and Neumann, Liberal Criminal Theory (Oxford: Hart Publishing, 2014). For Moore's views, see M Moore, Placing Blame (Oxford: Oxford University Press, 1997), pp. 27-30.
} 
contribute, unless at least some people fail to conform to those laws. ${ }^{11}$ One might ask why anyone would create LMBs. One might ask, in other words, why conviction would ever be a primary rather than a secondary means of achieving criminalization's ends. One answer returns us to $(\mathrm{E})$ :

(E) It is always a good reason in support of criminalization that it will probably result in just punishment of wrongdoers.

Now it is a common complaint of journalists and politicians that the criminal law punishes too few wrongdoers: that too many paedophiles, fraudsters, terrorists, and others 'get away with it' and escape the justice that criminal courts are set up to deliver. One explanation of this shortfall points to obstacles placed by rules of criminal procedure and evidence in the way of conviction. Those obstacles might, of course, be reduced by changes to procedural and evidential rules themselves. But they can also be circumvented by the creation of new crimes. It can be hard to prove beyond a reasonable doubt, using admissible evidence, that A manipulated or coerced B-her fellow minor-into engaging in sexual activity. It can be hard to prove that $\mathrm{C}$ was planning a terrorist attack, or that $\mathrm{D}$ incited others to commit acts of terrorism. It is much easier to prove that sexual activity took place between $\mathrm{A}$ and $\mathrm{B}$, both of whom are minors; that $\mathrm{C}$ possessed information likely to be useful to terrorists; or that $\mathrm{D}$ made a statement she realized might be taken by others to praise terrorist acts. By criminalizing that which is easier to prove, we reduce the obstacles that rules of criminal procedure and evidence place in the path of prosecutors. We thereby make it easier to convict wrongdoers-including manipulators, coercers, planners, and inciters-whose wrongdoing is difficult to prove. And we may also eliminate the need to prove anything at all. Potential defendants who can see that they have little chance of avoiding conviction if they plead not guilty are more likely to take the incentives they have to enter a guilty plea.

Imagine we do criminalize that which - in each of my pairs of examples-is easier to prove. $^{12}$ One might say that this will result in a great deal of unjust punishment. Ceteris paribus, there is no justice in punishing minors who engage in consensual sexual activity, those who order bomb-making manuals on the internet to indulge their curiosity, or those who stand up in public debate for the use of violence designed to depose tyrannical regimes. It does not follow, however, that, because these acts are crimes, the aforementioned actors will routinely be punished. Police officers may be instructed not to arrest, and prosecutors may be instructed not to prosecute, those whose criminal conduct is deemed morally innocuous. They may be instructed to arrest and prosecute only those offenders who are manipulators, coercers, planners, and inciters too. Imagine that these instructions are followed. Those whose punishment would be unjust will then largely be left alone. And those who are justly punished may be punished more frequently than if we had merely criminalized the wrongs that make it just to punish them: if we had criminalized

\footnotetext{
11 I assume that the ideal is not to convict people who committed no crimes.

12 This is what has occurred in English law. Sections 9 and 13 of the Sexual Offences Act 2003 make consensual sexual activity between minors a criminal offence. Sexual activity extends to kissing and touching through clothes (see, e.g., Lamb [2007] EWCA Crim 1766), so the formative sexual experiences of the vast majority of the population are now offences. Section 58 of the Terrorism Act 2000 makes it an offence to possess information of a kind likely to be useful to a person preparing an act of terrorism. Section 1 of the Terrorism Act 2006 makes it an offence to praise acts of terrorism (occurring in any place, at any time) if someone in the audience might infer that the speaker favours emulation, and the speaker appreciates the risk. For the purposes of the last two offences, acts of terrorism include acts that threaten to seriously damage property or electronic systems, if they are designed to influence the government, and to promote a political cause (section 1 of the Terrorism Act 2000).
} 
manipulation, coercion, planning, or incitement themselves. We have already seen why. If it is a crime to possess information likely to be useful to terrorists, it is much easier for prosecutors to secure the conviction of those identified as having planned terrorist attacks-much easier, that is, than it would have been if planning itself had been criminalized. First, because a crime of possession deprives planners of any right to proof that they did any planning. Planning is no part of the crime, so no evidence of a plan need be provided. Second, because more planners will plead guilty to a possession offence. As information of the relevant kind is possessed by almost all of us, the chances of an acquittal are extremely low. The lower the chances of acquittal, the stronger the incentive to plead guilty. All the more so when significant sentence reductions are available to those who do.

Now consider a law-maker who is thinking about what to criminalize in pursuit of the end mentioned in (E). And imagine that this law-maker is convinced both by the common complaint about the criminal justice system mentioned above, and that prosecutors can reliably identify wrongdoers if so instructed. Such a law-maker might well believe that the best way to further $(\mathrm{E})$ would be to extend the criminal law in the ways we have been discussing: to criminalize all sexual activity between minors, or possession of any information likely to be useful to terrorists, or any statement that the speaker realizes might be taken to be supportive of terrorism. More just punishments will be imposed, our law-maker might well believe, if this is what is criminalized. These considerations give us a first explanation of why LMBs might be created — of why, that is, conviction might be a primary rather than a secondary means of achieving criminalization's ends. Law-makersat least if they aspire to make law for something that passes for a liberal democracy-could not possibly intend to achieve their ends by means of compliance with the laws just mentioned. They could not intend that all minors cease to experiment sexually, that no-one ever possess anything that might be put to use for the purposes of terror, or that we all cease to contribute to public debate whenever someone might take our contribution to be supportive of politically motivated violence. Yet law-makers might well create the crimes under discussion to further end (E). Because their intention in doing so would be to further that end primarily by means of conviction, not compliance, we have an explanation of why law-makers might create LMBs. ${ }^{13}$

It is worth noting that LMBs need not only be created to further responsive ends like (E). They might also be created to further preventive ends like those mentioned in (A)-(C). We already saw that LMBs may facilitate the arrest, prosecution, conviction, and punishment of more of those thought to have committed harmful or seriously offensive wrongs. They may also facilitate the arrest, prosecution, convict, and punishment of more of those thought likely to commit such wrongs in future. LMBs may thereby contribute to both specific and general deterrence. The aim, once again, is not to bring this about primarily by means of compliance. It is to bring it about by means of a pattern of increased enforcement made transparent to, and imposed upon, those inclined to commit wrongs. A law-maker might well think that this LMB-generated pattern is a better preventer of wrongs than an LMF. So she might well enact an LMB to further the ends mentioned in (A)-(C). This gives us a second explanation of why law-makers might create such laws.

\footnotetext{
${ }^{13}$ LMBs are a sub-class of the larger class made up of so-called 'proxy offences.' The latter criminalize acts that are not the acts that law-makers ultimately aim to prevent. So the class of proxy offences includes inchoate offences (like attempted murder) that are created to prevent completed offences (like murder). Some proxy offences are LMFs not LMBs. They are meant to prevent harmful wrongs (like murder) by preventing the acts they criminalize (like attempted murder). They are meant to contribute to criminalization's ends primarily by means of conformity.
} 
Let us recap. I have distinguished between two possible means of achieving the ends of criminalization. The first possibility is that law-makers seek to achieve those ends primarily_ideally_by means of compliance. The second possibility is that law-makers seek to achieve those ends primarily_ideally_by means of conviction. Those who adopt the first means create laws that are made to be followed (LMFs). Those who adopt the second create laws that are made to be broken (LMBs).

I also sketched an argument for the creation of LMBs. That argument is in part an argument from justice. Some reply that to seek justice via LMBs is self-defeating. One version of this reply has it that LMBs cannot deliver just punishment even in principle. Punishment is just, so the argument goes, only when it communicates deserved censure. What punishment communicates depends on the crime for which one is punished. If what is criminalized is not a wrong that makes one eligible for punishment, one's punishment cannot communicate the censure one deserves. So it cannot be just. A second version has it that, even if LMBs are in principle capable of delivering just punishment, they will in practice result in many unjust punishments. They will do so, according to this argument, because prosecutors will make mistakes about which offenders are eligible for punishment. And because LMBs eliminate the requirement that wrongdoing-manipulation, coercion, planning, etc.-be proved in court, fewer of those mistakes will be corrected and more people will be unjustly punished. This is a moral loss, it is concluded, that outweighs any moral gain produced by additional just punishments.

In the remainder of this paper, I offer a reply of a different kind. I grant for the sake of argument that LMBs may lead to more just punishment than LMFs. I do not, in other words, argue that enacting such laws in pursuit of just punishment is always self-defeating. Instead, I argue that whatever justice may be produced by LMBs is justice law-makers must not seek if they are to govern in accordance with the ideal of the rule of law. If I am right, it is part of the price of living under the rule of law that we give up on the gainsincluding gains in justice - that might be achieved via the enactment of such laws.

\section{The Identification Principle}

The rule of law is often thought of as an ideal for laws and legal systems. So understood, it requires that those subject to the law can reliably be guided by it. ${ }^{14}$ The rule of law is, however, also an ideal for states. So understood, it requires that state officials, and state institutions, are subject to the law. It also requires that their conduct is guided by the laws to which they are subject. This second requirement, simply stated, is unhelpfully vague. I try in what follows to make one aspect of it more precise. I argue that conformity to the second requirement requires conformity to what I call the 'identification principle.' Lawmakers who create LMBs violate that principle.

All legal systems confer powers to impose duties on persons generally, such as powers to prohibit murder, burglary, or rape. All legal systems also confer powers to impose duties on particular individuals, such as powers to arrest, prosecute, convict, and punish. Different powers are conferred on different officials and institutions. Criminal courts have the power to convict but not to arrest. Police officers have the power to arrest but not to convict. Each power may lawfully be exercised only when certain triggering conditions are met. Police constables lawfully arrest $p$ for some offence without a warrant only if they suspect $p$ of

${ }^{14}$ For classic discussion, see L Fuller, The Morality of Law (rev edn, New Haven: Yale University Press, 1969) ch. 2; J Raz, The Authority of Law (2nd edn, Oxford: Oxford University Press, 2009) ch. 11. 
committing that offence, and only if they have reasonable grounds for the suspicion. Criminal courts lawfully convict $p$ of some offence only if $p$ pleads guilty, or the members of the jury (or enough of them) conclude that they are sure $p$ committed the offence, and reach this conclusion on the grounds of the evidence admitted at trial.

Let us say that, in cases of the kind just described, the state's imposition of new duties on particular individuals is legally regulated. It is legally regulated in virtue of the following facts:

a. specified officials (police officers) or institutions (courts) are empowered by law to impose particular duties;

b. those powers are lawfully exercised only if certain triggering conditions are met;

c. the triggering conditions require, inter alia, a specified degree of confidence (lack of reasonable doubt) on specified grounds (evidence presented at trial) in specified facts (that $p$ committed the offence).

I earlier claimed that, if we are to have the rule of law, state officials and institutions must be subject to the law. Legal regulation of the kind just mentioned helps to satisfy this requirement. I also claimed that the law must guide the conduct of state officials and institutions. To determine whether the state is meeting this requirement, we can ask two questions. First, and most obviously, we can ask whether state officials or institutions are violating the law. If the imposition of new duties is legally regulated, the law is violated if the applicable triggering conditions are breached. Second, and less obviously, we can ask how officials and institutions identify those on whom new duties ought to be imposed. My concern in the remainder of this section is with this second question.

Let us assume from now on that we are dealing with duties - call them ' $d$ ' - the imposition of which is legally regulated. How is the state to decide if $d$ ought to be imposed on $p$ ? One possibility is to look to the officials or institutions empowered to impose $d$. According to the identification principle, state officials and institutions may decide that $p$ is someone on whom $d$ should be imposed only if the officials or institutions empowered to impose $d$ on $p$ have determined that the applicable triggering conditions are satisfied in $p$ 's case. If no such determination has been made, all state officials and institutions must treat $p$ as someone on whom $d$ ought not to be imposed, and who is to be protected against $d$ 's imposition. ${ }^{15}$

You may ask to what exactly the identification principle is opposed. To see the answer, consider a police officer who arrests $p$ for assault, and does have reasonable grounds to suspect $p$ of the offence. This officer does not violate the triggering conditions when she arrests $p$. So the arrest is not unlawful. It does not follow that $p$ was identified as someone who ought to be arrested only when grounds for reasonable suspicion were found. It may already have been decided, by the officer or by others, that $p$ is someone who ought to be arrested. It may be, as I will put it from now on, that $p$ was 'pre-identified' for arrest: that she was identified as someone who ought to be arrested, in advance of the police determining that there were reasonable grounds to suspect her of the assault for which she was ultimately arrested. Indeed, it may have been precisely because she was pre-identified in this way that reasonable grounds to suspect her of assault were later found. When this is so, $p$ is treated by the state not as a protectee but as a target: steps are taken to make it the case that $p$ can lawfully be arrested because it has already been decided that this ought to occur;

\footnotetext{
15 Consider the example of conviction. The law empowers criminal courts to convict. Where $p$ pleads not guilty, a court may do so only if the jurors (or enough of them) conclude that they are sure, on the admitted evidence, that $p$ committed the offence. The identification principle requires that no state official or institution decide, in advance of such a conclusion, that $p$ ought to be convicted.
} 
those steps are taken despite the fact that those empowered to arrest $p$ have not yet determined that the triggering conditions for the exercise of that power are met.

Several types of pre-identification are worth distinguishing. To distinguish them, let us consider some examples. We can start with:

Constable-A police constable arrives at the scene of a physical altercation. Seeing that $p$ has a tattoo, she immediately decides $p$ probably committed assault and ought to be arrested. As a result, she looks for evidence of $p$ having offended, and, on finding reasonable grounds for suspicion, makes the arrest.

In Constable, the official in question is empowered to arrest $p$. She has the degree of confidence specified by the applicable triggering conditions from the moment she sees p. But she lacks the legally specified grounds-namely, reasonable ones-for her suspicion. When she identifies $p$ as someone who ought to be arrested, in the absence of those grounds, she pre-identifies $p$. Now consider:

Juror - Having heard the prosecution's case, a juror decides it is more likely than not that $p$ committed the crime with which she is charged. The juror concludes that this is enough to establish that $p$ ought to be convicted, and sets about persuading her fellow jurors to convict $p$.

In Juror, the initial decision about $p$ is again not reached on the legally specified groundsit is not reached on the basis of all the evidence presented at trial. What's more, $p$ is identified as someone who ought to be convicted despite our juror lacking the legally specified degree of confidence in the specified facts-despite, that is, her not being sure $p$ committed the offence. ${ }^{16}$ Once again, $p$ is pre-identified. Now take a third case:

Magistrate-Having heard all the evidence, a magistrate is sure that $p$ committed adultery, but is not sure that $p$ committed the sexual assault with which she is charged. She decides that $p$ ought to be convicted, and sets about persuading her fellow magistrates to convict $p$.

In Magistrate, the official in question is again empowered to convict $p$. She has the degree of confidence specified by the triggering conditions. Let us assume she has it on the specified grounds - on the basis of the evidence presented at trial. Nonetheless, she does not have that degree of confidence in the specified facts, namely that $p$ committed sexual assault. So, when she decides $p$ ought to be convicted, she pre-identifies $p$. Here is a fourth case:

Mayor-The local major suspects $p$ of assault. She decides $p$ ought to be arrested, and tells the police to look for evidence that $p$ offended. The police are able to find reasonable grounds to suspect $p$, and they make the arrest.

In Mayor, an official identifies $p$ as someone who ought to be arrested, despite having no legal power to arrest p. ${ }^{17}$ The mayor does possess the legally specified degree of confidence that $p$ committed assault. Let us assume she possesses that confidence on the specified grounds. Nonetheless, she is not legally empowered to make arrests. So $p$ is preidentified as soon as the mayor decides $p$ ought to be arrested. Consider one final example:

\footnotetext{
${ }^{16}$ Notice that if she persuades enough of her fellow jurors, our original juror need not herself vote to convict. So she need not violate the triggering condition that requires her to vote this way only if she is sure $p$ committed the offence.

17 I assume here that ordinary citizens only have the power to arrest for indictable offences. Assault is not such an offence.
} 
Proof-A police officer has reasonable grounds to suspect $p$ of a string of robberies, and decides that as a result $p$ ought to be convicted. Worried that the prosecution will be unable to prove that $p$ was the perpetrator, she looks for evidence of $p$ having committed some other crime. Finding evidence of assault, she makes the arrest. When $p$ 's case reaches court, $p$ is convicted of assault.

Proof is a case that shares features of all that went before it. Notice that $p$ is identified by a police officer as someone who ought to be convicted. Only the criminal courts are empowered to convict criminals. They do so lawfully only if the defendant pleads guilty, or the members of the jury (or enough of them) are sure, on the evidence admitted at trial, that the defendant committed the offence. As in Mayor, $p$ is identified as someone on whom $d$ ought to be imposed not by those empowered to impose $d$ - the courts-but by anotherthe police officer who makes the arrest. As in Constable, $p$ is not identified on the legally specified grounds - here, the evidence presented at trial-but beforehand, on whatever grounds the police officer has to suspect $p$. As in Juror, those doing the identifying lack the specified degree of confidence-the absence of reasonable doubt-and possess only a lesser degree-suspicion. And as in Magistrate, $p$ is not identified on the basis of official confidence in the specified facts. As $p$ is charged with assault, the specified facts are facts that constitute commission of that offence. But $p$ is identified as someone who ought to be convicted on the basis of the police officer's confidence in another fact entirely-a robbery for which $p$ is never arrested or charged. For all these reasons, the police officer in Proof pre-identifies $p$.

Though these cases differ in various respects, they are all cases of pre-identification. In each case, $p$ is identified as someone on whom $d$ ought to be imposed before the official or institution empowered to impose $d$ comes to have the legally specified degree of confidence, in the legally specified facts, on the legally specified grounds. And in each case, once $p$ has been pre-identified, steps are taken to make it the case that $d$ can lawfully be imposed-to make it the case that those empowered to arrest or convict $p$ will be able to do so without violating the applicable triggering conditions. As I already observed, to take these steps is to treat $p$ as a target, rather than as someone to be protected against $d$.

It is pre-identification of all kinds to which the identification principle is opposed. State officials and institutions are not to identify $p$ as someone on whom $d$ ought to be imposed, unless those empowered to impose $d$ have determined that the triggering conditions are satisfied. So it is police officers who must decide who ought to be arrested, and courts who must decide who ought to be convicted. Their decisions must await application of the triggering conditions provided for by law. It follows that, when the identification principle is upheld, the state divides its people up in a particular way: those on whom $d$ should be imposed are distinguished from those on whom $d$ should not, by legally empowered officials and institutions, using legally specified conditions, on legally specified grounds. I mentioned earlier that the rule of law requires that the law guide state conduct. We can now see why the identification principle is itself one aspect of that requirement.

It may be said that the identification principle has a more familiar name than the one I have given it here - that it is one aspect of the ideal known as equality before the law. It is true that a certain type of equality is a byproduct of conformity to the principle under discussion. When it comes to duties the imposition of which is legally regulated, conformity to the identification principle puts every individual in the same position: until those empowered to impose $d$ determine that the triggering conditions are satisfied, no state official will conclude that $d$ ought to be imposed on anyone. Because all are protected against pre-identification, all are equal in this respect. But we should not conclude from 
this that we are dealing with an egalitarian principle. Egalitarian principles determine what ought to be done to $p$ by reference to $p$ 's relative position-by asking whether $p$ is worse or better off than $q$ in some respect. It follows that one cannot know what an egalitarian principle requires in $p$ 's case without knowing how others are positioned in the relevant respect. ${ }^{18}$ The identification principle is not like this. In the case of any given individual, officials need know nothing about the position of others in order to conform to that principle. All officials need know is that they must not conclude that $d$ ought to be imposed on $p$, unless and until those empowered to impose $d$ so conclude by applying the law to $p$ 's case.

What is the case for the identification principle? Compare a world in which the state conforms to that principle with one in which it is violated. In the world of conformity, the state's decision-making is made transparent in the following way: when the state identifies those on whom duties ought to be imposed, it does so using criteria (which I have been calling the triggering conditions) found in the law. Assuming that-as the rule of law also requires - the law is adequately publicized, those criteria are exposed to public view. In such a world, the state cannot use particular criteria to divide us up-into those who should and should not be arrested, convicted, etc.- -without making those criteria public. It must be willing to face up to the critical reaction that might result. What's more, because the criteria used by the state are legal ones, the state's application of those criteria is subject to legal challenge. Most obviously, $p$ can require that those facts taken to make it the case that $p$ ought to be convicted are proved in court beyond a reasonable doubt.

In the world of violation, things are different. The criteria used to decide if $d$ ought to be imposed on $p$ are found outside the law. People are identified for arrest on the basis of their tattoos, or for conviction on the basis of their adultery. And the criteria used can, of course, be sinister in other ways. We might be divided up by the state-into those who should and should not be arrested or convicted-on the basis of suspicions about our political convictions or religious leanings. These criteria need never find their way into the law. So they need never be exposed to public view. ${ }^{19}$ Nor is it easy to challenge the application of those criteria. In Magistrate, it is $p$ 's alleged adultery that is taken to justify bringing about her conviction. But $p$ is not on trial for adultery, so she cannot require proof of it. In Constable, it is the presence of a tattoo that is taken to justify bringing about $p$ 's arrest. But the tattoo is not relied on to provide reasonable grounds for suspicion. It provides no part of the case for the lawfulness of $p$ 's arrest. The general point here is this: for the reasons I have given, the biases and prejudices of state officials and institutions are more likely to remain hidden in a world in which the identification principle is violated. And they are less likely to be successfully challenged by those who suffer in consequence. This is one reason to favour the world of conformity.

The lack of transparency that exists when the identification principle is violated is important for a second reason. It is important because it increases the risk that we will be ambushed by the law. In the world of conformity, the decision that $p$ ought to be arrested will be made only if the police conclude that there are reasonable grounds to suspect $p$ of an offence. Absent that decision, all are to be protected against arrest. Assuming again that

\footnotetext{
18 For general doubts about egalitarian principles, see J Raz, The Morality of Freedom (Oxford: Oxford University Press, 1986) ch. 9; P Westen, “The Empty Idea of Equality” Harvard LR 95 (1982), pp. 537-596.

19 There remain legal criteria, of course, in the form of the applicable triggering conditions. But, in the world of violation, decisions about who ought to be arrested (or prosecuted or convicted) are not made using those criteria. The decisions are made in advance, and steps are then taken to ensure that the criteria are satisfied.
} 
the law is adequately publicized, arrest is something we have a decent opportunity to anticipate and avoid. In the world of violation, the decision that we ought to be arrested may be made on other grounds (which are not reasonable), on the basis of other facts (which are not offences), and by other officials (who are not the police). Once that decision is made, we become targets of the state, and steps are taken to make it the case that we can be lawfully arrested. In this second world, it is far harder to reliably steer one's life away from adverse legal consequences of this kind. It is far more likely that one will be ambushed by arrest, conviction, or punishment that one could not reasonably avoid or foresee.

There is a third reason to value the identification principle. When that principle is upheld, decisions about the imposition of $d$ are made in particular places, by means of particular processes. Most obviously, decisions about who should be convicted are made in the courts, using evidence presented by both sides at trial. This makes it the case that the state's decision about whether to impose $d$ on $p$ is one in which $p$ has the opportunity to participate. She participates by presenting evidence taken into account by those who make that decision. In Jeremy Waldron's words, when the state makes decisions in this way it 'allows people a voice, a way of intervening on their own behalf in confrontations with power. ${ }^{20}$ It thereby treats people subject to the law 'as though they had a view of their own to present on the application of a given norm to their conduct or situation.' This, Waldron concludes, is to adopt 'a mode of governing people that treats them with respect. ${ }^{21}$

It is true, of course, that to violate the identification principle is not (or need not be) to do away with trials. But as my examples showed, it may be to do away with trials in which all the evidence is presented before decisions are made about who should be convicted (think of Juror). And it may be to do away with trials in which decisions about conviction are made on the basis of the offence charged (think of Magistrate). It may even be to do away with trials in which such decisions are reserved for the courtroom (think of Proof). By doing away with such trials, we reduce the extent to the state governs in the manner described by Waldron. We reduce the extent to which decisions made about $p$ are made with $p$ 's participation — on the basis of evidence and argument offered by, and to, $p$ in the courts. So we reduce the ability of each person to intervene 'on their own behalf in confrontations with power.'

\section{Identification and LMBs}

The previous section introduced and defended the identification principle. The present section argues that the creation of LMBs violates that principle.

An argument of this kind may not seem promising. One may be forgiven for thinking that the identification principle is a principle that tells officials and institutions how to apply and enforce the law. It does so by telling them that their decisions about who ought to be arrested and convicted are not to be made in advance of their application of the triggering conditions. When officials or institutions make new law, they change the triggering conditions. New offences add new entries to the list of legally specified facts. Those who criminalize robbery add acts that constitute robbery. They do so in order to make it the

\footnotetext{
20 J Waldron, "The Concept and the Rule of Law" Georgia Law Review 43 (2008), p. 8.

21 Ibid., p. 23.
} 
case that robbers may lawfully be arrested or convicted. ${ }^{22}$ This might seem to generate the following problem. If the identification principle applies to law-making, even criminalizing robbery turns out to be a violation of the rule of law, because it pre-identifies robbers as people who ought to be convicted. This, surely, proves too much. If, on the other hand, the principle applies only to law-enforcers and appliers, the principle cannot be relevant to the creation of LMBs. So the argument I have promised here must miss the mark.

The dilemma posed in the previous paragraph fails to bite. I claimed above that the identification principle applies to all state officials and institutions. This is to say that it applies to law-enforcers, law-appliers, and law-makers alike. Does this imply that even criminalization of robbery is a violation of the rule of law? It does not. Imagine we are lawmakers who endorse the identification principle. In virtue of this endorsement, we believe it is for the courts - and not for us - to decide whether any given individual ought to be convicted. The courts are to make such decisions using the applicable triggering conditions. We nonetheless have the power, by making new law, to change those triggering conditions. To exercise that power responsibly, we must exercise it in ways that we think will further criminalization's ends. Let's say we think that convicting robbers is a means of furthering those ends. The identification principle does not preclude criminalization. It merely requires that we leave the question of whether anyone is a robber to the courts. We do just that by criminalizing robbery. If this is what we criminalize, application of the triggering conditions we put in place itself divides those whose conviction we seek to bring about, namely robbers, from those whose conviction we seek to avoid. The task of carrying out this division is delegated to the courts. By criminalizing in this way, we conform to, rather than violate, the identification principle.

Consider now a case of law-making that violates the identification principle. Imagine again that we are law-makers who think that convicting robbers will further criminalization's ends. Let's say we are confident that $p$ has already committed robbery and decide that $p$ ought to be convicted as a result. To bring this about, we might simply enact a law declaring that $p$ is guilty. Alternatively, we might make it less obvious that we are targeting $p$. We might enact a law making it a crime to be present somewhere we know $p$ is (likely to be) present, or to be part of a group of which we know $p$ is (likely to be) part. Enacting such laws makes $p$ 's conviction more likely to occur. Rather than leaving it to the courts to decide whether $p$ really is someone who ought, in our view, to be convicted-whether, that is, $p$ is the robber we suspect her of being-we enact laws the effect of which is to remove that decision from the courts. ${ }^{23}$ Because of the triggering conditions we put in place, the court in which $p$ is tried will only determine that $p$ is $p$, or was present somewhere, or was part of some group. It will not determine that $p$ robbed anyone of anything. It will not do so because the offence for which $p$ is tried was created with the assumption that $p$ ought to be convicted built into it. That assumption explains why the offence takes the shape it does, and why the court is not invited to consider whether $p$ committed robbery. Law-makers who create such laws pre-identify $p$. They turn her into someone targeted for conviction by the very laws applied to her case.

We can now return to LMBs. My examples included laws criminalizing all sexual activity between minors, and criminalizing possession of any information likely to be

\footnotetext{
22 Though this may, as we saw above, be no more than a fallback.

23 I assume here that, in applying the offences in question to $p$ 's case, the courts cannot simply add facts to the list of triggering conditions at will. This is undoubtedly the case if the offence they are applying is found in primary legislation, and if the legal system of which they are part contains a doctrine of legislative supremacy.
} 
useful to terrorists. Such laws are enacted because it is assumed that some of those who violate them will have manipulated or coerced fellow minors, or will have been planning terrorist attacks. These wrongdoers are to be identified by police officers and prosecutors. Other offenders are to be left alone. Because manipulation, coercion, and planning need not be proved in court, it is assumed that more manipulators, coercers, and planners can be convicted. The increased conviction rate is meant to further the criminal law's responsive ends by bringing about more just punishment. It is meant to further the criminal law's preventive ends by deterring those who might otherwise have committed harmful or seriously offensive wrongs.

We can now see why the enactment of LMBs violates the identification principle. Unlike the law-makers described two paragraphs ago, those who enact LMBs do not have a particular individual in mind at the time of enactment. But they do have in mind that wrongdoers who ought to be convicted will exist in future, and that some of them will be identified by police and by prosecutors. These law-makers do not leave it to the courts to decide whether $p$ 's conduct makes her, in the law-makers' view, someone who ought to be convicted-whether, that is, $p$ is the manipulator, coercer, or planner she is suspected of being. Instead, they enact laws the effect of which is to remove that decision from the courts. Because of the triggering conditions LMBs put in place, $p$ 's trial need only determine that $p$ engaged in the kind of sexual activity in which almost everyone engages, or possessed something of a kind that almost everyone possesses. It need not determine that $p$ was a manipulator, coercer, or planner. ${ }^{24}$ It need not do this because the very offence for which $p$ is tried is an offence that was created on the assumption that $p$ would be someone who ought to be convicted. That assumption explains why the offence takes the shape it does, and why proof that $p$ manipulated, coerced, or planned is not required. Law-makers who create such laws pre-identify $p$. They turn her into someone targeted for conviction by the very laws applied to her case.

I earlier mentioned three reasons why conformity to the identification principle is of value. All three are reasons for the state not to enact LMBs. The first was that violation of that principle helps bias and prejudice remain hidden, as well as helping to immunize it against legal challenge. In the case of LMBs, police officers and prosecutors are relied on by law-makers to determine which offending acts are, and which are not, worthy of arrest or prosecution. They are relied on to use criteria that include a measure confidence in facts about $p$, such as the fact that $p$ is a manipulator, coercer, or planner. But these criteria are not-and are not meant to be-the triggering conditions found in the law. So criteria which themselves exhibit bias or prejudice are less visible. And biased or prejudiced application of the criteria is harder for the courts to expose, because there is no need for prosecutors to prove that the criteria they use are in fact satisfied. For this very reason, those suspected of satisfying whatever criteria are being applied are less able to challenge the suspicion. It follows that, as well as helping bias and prejudice to remain hidden from view, LMBs also make it more likely that victims of both these ills will be convicted and punished.

\footnotetext{
24 'Need not' because $p$ has no right to a determination of this kind. True, it is always open to a court to hold that $p$ 's trial is an abuse of process. But the courts have consistently held that their power to stay proceedings is to be used only in the rarest of cases (see, e.g., $R v$ Horseferry Road Magistrates' Court, ex $p$ Bennett [1993] 3 All ER 138, 161, 163 per Lord Lowry). To succeed, $p$ must show that the decision to prosecute was one that no reasonable prosecutor could have taken. In some cases, published prosecutorial guidelines have been used to challenge prosecutions on this basis. But such guidance does not always exist. It can be withdrawn. And because the bar is set so high, the challenges in question rarely succeed (see, e.g., $S$ v DPP [2006] EWHC 2231 (Admin)).
} 
I mentioned above that violation of the identification principle reduces our chances of anticipating and avoiding conviction. It increases the likelihood that we will be ambushed by the law. This was the second reason I gave to value conformity to that principle. The risk of ambush is particularly acute when LMBs are enacted. Recall that such laws - unlike LMFs - are not meant to contribute to criminalization's ends by means of conformity. So their creators lack incentives to only criminalize acts that, in their view, ought not to be performed. In fact, they have incentives to criminalize a wider range of activities-including those widely engaged in—so that, when $p$ is identified by police and prosecutors as worthy of conviction, she can be lawfully arrested and prosecuted. For the very same reason, there is little incentive to publicize LMBs. ${ }^{25}$ But it is obvious enough that the wider the range of ordinary activities we criminalize, and the less publicity our law-making activities receive, the more likely people are to stumble unwittingly into criminality. We already saw that LMBs make the criteria used to decide who will be arrested and prosecuted hard to detect. They do so by taking those criteria outside of the law. The risk that we will be ambushed by arrest and prosecution is then all the greater. And precisely because we are likely to have already stumbled unwittingly into the commission of crime, we can have little confidence that conviction and punishment will not be the outcome.

I gave a third reason to value conformity to the identification principle: that it helps give people a voice in their confrontations with state power. It does so by enabling people to participate in decisions about whether they ought to be arrested, prosecuted, convicted, or punished. LMBs frustrate that participation in the following way. The decision that $p$ ought to be convicted - the decision that explains why $p$ is in court at all —is a decision made on the grounds that $p$ manipulated, coerced, planned, or committed some other wrong. But the decision that $p$ is a manipulator, coercer, or planner is not made in the courtroom. It is not made there because the offence with which $p$ is charged makes no reference to the aforementioned wrongs. So the question of whether $p$ committed those wrongs is not at stake in $p$ 's trial. This is to reduce $p$ 's participation in the most important decision made about her-the one that explains why she, and not hundreds or thousands of other offenders, is in danger of conviction. I quoted Waldron to the effect that criminal trials are of value partly because they give people 'a way of intervening on their own behalf in confrontations with power.' It is perhaps the most striking cost of LMBs that they drastically reduce our ability to intervene in this way.

\section{Conclusion}

I have offered an argument against the enactment of LMBs. My argument has been that they violate what I called the 'identification principle.' I argued that the identification principle is an implication of the ideal of the rule of law. It is also a principle of justice. As others have observed, principles of justice are allocative principles. ${ }^{26}$ They tell us who should get what and why. The allocative principles most discussed by criminal lawyers are principles of just punishment. We can more clearly see the allocative task performed by the identification principle by contrasting it with such principles.

\footnotetext{
${ }^{25}$ So it is no surprise that one conclusion of the Stern Review into the Sexual Offences Act 2003 was that very little had been done to publicize the offences applicable to young people.

${ }^{26}$ For this observation, see, e.g., J Rawls, A Theory of Justice (rev edn, Oxford: Oxford University Press, 1999), p. 7; J Gardner, Law as a Leap of Faith (Oxford: Oxford University Press, 2012), ch. 10.
} 
To punish is necessarily to allocate suffering or deprivation to wrongdoers for their wrongs. Principles of just punishment tell us why wrongdoing is a reason to punish wrongdoers in the first place. For some, this is because allocating suffering or deprivation to wrongdoers is, without more, an appropriate response to wrongdoing. On this view, the fact that wrongdoing has come into the world is always a reason to bring more suffering or deprivation into the world alongside it. ${ }^{27}$ For others, there is reason to punish wrongdoers only when, and because, some suffering or deprivation will come into the world whatever we do. It is often true that victims will suffer if we do not punish wrongdoers (in virtue of becoming victims), while wrongdoers will suffer if we do (in virtue of being punished). Some think that it is only in conditions like these-where not all suffering can be avoided-that it is appropriate to allocate suffering to wrongdoers. ${ }^{28}$ People who hold the first view think we have reasons to punish wrongdoers because (with limits) this is valuable in itself. People who hold the second view think we have reasons to punish wrongdoers because someone will suffer come what may, and because (within limits) wrongdoers have less of a complaint about being the ones who suffer.

The identification principle does not tell us what counts as a good reason to impose suffering on wrongdoers for their wrongs. So it is not a principle of just punishment. Instead, it carries out a rather different allocative task. It does so by imposing a condition that must be satisfied before state officials or institutions may target $p$ for punishment (or arrest, prosecution, or conviction) - before, that is, they may decide that $p$ ought to be punished (or arrested, prosecuted, or convicted), and take steps to bring it about that this occurs. State officials must not target $p$ until those empowered to punish (or arrest, prosecute, or convict) $p$ have determined that $p$ satisfies the triggering conditions provided for by law. To endorse the identification principle is to hold that, as long as such a determination has not been made in $p$ 's case, there are good reasons for the state to protect $p$ against punishment (as well as against arrest, prosecution, and conviction). As I put it above, the state is to treat $p$ not as a target but as a protectee. The allocative task carried out by the identification principle is thus the task of allocating a particular type of protection. The state is to provide protection against punishment (and arrest, prosecution, and conviction) to all who have not been identified in accordance with the identification principle.

The argument of Sects. 2 and 3 was in part an argument for conformity to that principle. I argued that the value of conformity is found in several places. Section 1 noted that one argument for violation is an argument from justice. It is an argument that we better conform to principles of just punishment by violating the identification principle and enacting LMBs. As I pointed out there, some argue that this is self-defeating. They claim that the punishments enacted pursuant to LMBs (or many of them) are unjust. Even if this is wrong, my comments in this section show that there are reasons of justice not to enact LMBs, because the identification principle is itself an allocative principle. So it is itself a principle of justice. This, however, was not the main point that I tried to make in this paper. The main point was that it is part of the price of living under the rule of law that the state is limited in the amount of justice it can do using the legal means at its disposal. One such limitation is given by the identification principle. And that principle condemns the creation of LMBs.

\footnotetext{
27 For this view, see M Moore, Placing Blame, chs. 2-4.

${ }^{28}$ For a view of this kind, see V Tadros, The Ends of Harm (Oxford: Oxford University Press, 2012), ch. 12.
} 
Open Access This article is distributed under the terms of the Creative Commons Attribution 4.0 International License (http://creativecommons.org/licenses/by/4.0/), which permits unrestricted use, distribution, and reproduction in any medium, provided you give appropriate credit to the original author(s) and the source, provide a link to the Creative Commons license, and indicate if changes were made. 